\title{
Predictive equations for lung volumes from computed tomography for size matching in pulmonary transplantation
}

\author{
Jeremy A. Konheim, MD, ${ }^{a}$ Zachary N. Kon, MD, ${ }^{\text {a }}$ Chetan Pasrija, MD, ${ }^{a}$ Qingyang Luo, PhD, ${ }^{b}$ \\ Pablo G. Sanchez, MD, PhD, ${ }^{\mathrm{a}}$ Jose P. Garcia, MD, ${ }^{\mathrm{c}}$ Bartley P. Griffith, MD, ${ }^{\mathrm{a}}$ and Jean Jeudy, MD ${ }^{\mathrm{d}}$
}

\begin{abstract}
Objective: Size matching for lung transplantation is widely accomplished using height comparisons between donors and recipients. This gross approximation allows for wide variation in lung size and, potentially, size mismatch. Three-dimensional computed tomography (3D-CT) volumetry comparisons could offer more accurate size matching. Although recipient $\mathrm{CT}$ scans are universally available, donor CT scans are rarely performed. Therefore, predicted donor lung volumes could be used for comparison to measured recipient lung volumes, but no such predictive equations exist. We aimed to use 3D-CT volumetry measurements from a normal patient population to generate equations for predicted total lung volume (pTLV), predicted right lung volume (pRLV), and predicted left lung volume ( $\mathrm{pLLV}$ ), for size-matching purposes.
\end{abstract}

Methods: Chest CT scans of 400 normal patients were retrospectively evaluated. 3D-CT volumetry was performed to measure total lung volume, right lung volume, and left lung volume of each patient, and predictive equations were generated. The fitted model was tested in a separate group of 100 patients. The model was externally validated by comparison of total lung volume with total lung capacity from pulmonary function tests in a subset of those patients.

Results: Age, gender, height, and race were independent predictors of lung volume. In the test group, there were strong linear correlations between predicted and actual lung volumes measured by 3D-CT volumetry for pTLV $(r=0.72)$, $\operatorname{pRLV}(r=0.72)$, and pLLV $(r=0.69)$. A strong linear correlation was also observed when comparing pTLV and total lung capacity $(r=0.82)$.

Conclusions: We successfully created a predictive model for pTLV, pRLV, and pLLV. These may serve as reference standards and predict donor lung volume for size matching in lung transplantation. ( $\mathrm{J}$ Thorac Cardiovasc Surg 2016;151:1163-9)

Size matching for lung transplantation is an important consideration and has a significant influence on clinical outcomes. Size mismatch has been shown to be associated with prolonged stay in intensive care units, persistent atelectasis, pneumothorax, hyperinflation, decreased maximum

\footnotetext{
From the ${ }^{\mathrm{a}}$ Divisions of Cardiac Surgery and ${ }^{\mathrm{d}}$ Thoracic Radiology, University of Maryland School of Medicine, Baltimore, Md; ${ }^{b}$ Division of Applied Health Services Research, Ochsner Clinic Foundation, New Orleans, La; and ${ }^{\mathrm{c}}$ Division of Cardiac Surgery, Massachusetts General Hospital, Boston, Mass.

Received for publication May 9, 2015; revisions received Sept 29, 2015; accepted for publication Oct 18, 2015; available ahead of print Dec 23, 2015.

Address for reprints: Chetan Pasrija, MD, Division of Cardiac Surgery, University of Maryland, 22 S Greene St, Baltimore, MD 21201 (E-mail: cpasrija@smail. umaryland.edu).

$0022-5223 / \$ 36.00$

Copyright (c) 2016 by The American Association for Thoracic Surgery

http://dx.doi.org/10.1016/j.jtcvs.2015.10.051
}

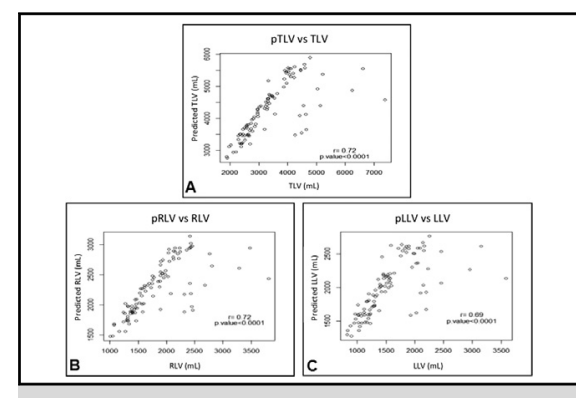

Predictive equations for total, right, and left lung volumes.

\section{Central Message}

To serve as references for lung transplant size matching, we created equations for lung volumes using 3D-CT volumetry.

\section{Perspective}

Currently, the most commonly used sizematching strategy in the United States is height comparison of donor and recipient. Studies have commented on the inaccuracy of this strategy. We created predictive equations that could be used for a new size-matching strategy, based on 3-dimensional computed tomography volumetry. These equations allow trial of a potentially more accurate size-matching strategy.

See Editorial Commentary page 1170 .

See Editorial page 916. exercise capacity, and earlier occurrence of bronchiolitis obliterans syndrome. ${ }^{1-3}$ Yet methods of size matching for lung transplantation remain crude.

The most widely accepted method for size matching uses height comparisons between donor and recipient. Height is a poor predictor of lung volume and therefore is a potentially inaccurate surrogate to use for size matching in lung transplantation. This may allow for wide variation

Scanning this QR code will take you to supplemental figures for this article.

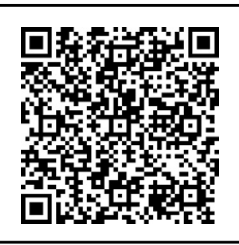




$$
\begin{aligned}
& \text { Abbreviations and Acronyms } \\
& \text { 3D-CT }=\text { 3-dimensional computed tomography } \\
& \text { CT }=\text { computed tomography } \\
& \text { LLV }=\text { left lung volume } \\
& \text { PFT }=\text { pulmonary function testing } \\
& \text { pLLV }=\text { predicted left lung volume } \\
& \text { pRLV }=\text { predicted right lung volume } \\
& \text { pTLC }=\text { predicted total lung capacity } \\
& \text { pTLV }=\text { predicted total lung volume } \\
& \text { RLV }=\text { right lung volume } \\
& \text { TLC }=\text { total lung capacity } \\
& \text { TLV }=\text { total lung volume }
\end{aligned}
$$

of actual donor and recipient lung volumes, resulting in significant size mismatch.

Three-dimensional computed tomography (3D-CT) volumetry is a new and reliable method of assessing lung volume, and has even been shown to be more reproducible then total lung capacity (TLC) measurements by pulmonary function tests (PFTs). ${ }^{4,5}$ This technology could potentially be used for size matching by comparing a transplant recipient's lung volume measured by 3D-CT volumetry with a transplant donor's predicted lung volume. Because 3D-CT volumetry allows for the right and left lungs to be evaluated separately, this method can be applied to single or double lung transplantation. However there presently are no predictive models established in the literature for lung volumes derived from this technique. We aimed to create predictive equations based on readily available donor demographic data for total lung volume (TLV), right lung volume (RLV), and left lung volume (LLV) extrapolated from 3D-CT volumetry.

\section{PATIENTS AND METHODS \\ Study Rationale}

To analyze the predictive ability of height as a surrogate for lung volume, a retrospective review of 104 consecutive lung transplantations performed at our institution from 2005 to 2010. Recipient height was found to have a very weak correlation with measured recipient TLV from pretransplant computed tomography (CT), and TLC from PFT (Figure 1). This suggests the inaccuracy of height as a sole determinant for size matching in lung transplantation and directed a potential need for a different size-matching strategy.

\section{Patients}

Institutional review board approval (HP-00045429) was obtained and a waiver of patient consent was granted. Consecutive chest CT scans of patients between ages 18 and 55 years that were performed between 2005 and 2010 were evaluated. CT scans were initially read and interpreted by a radiologist at the time the scan was completed, and again, retrospectively, by a radiologist who specializes in thoracic radiology (JJ). CT scans that were read as abnormal, with evidence of pulmonary or cardiac disease (including radiologic findings suggestive of restrictive or obstructive disease, pleural or parenchymal abnormalities, atelectasis,

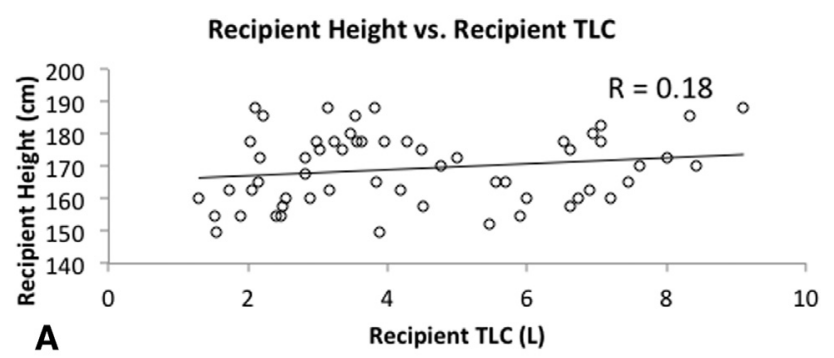

Recipient Height vs. Recipient TLV

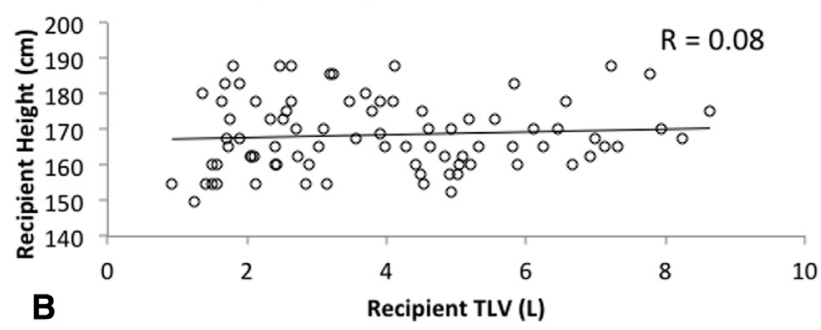

FIGURE 1. Correlation between lung transplant recipient height and A, Total lung capacity $(T L C)$ and B, Total lung volume (TLV).

scarring, pneumothorax, cardiomegaly, or more than 2 subcentimeter nodules or masses), by either radiologist were excluded.

Patients who were determined to be at suboptimal inspiration were excluded from the study, because previous literature demonstrates that PFT and 3D-CT volumetry show the greatest correlation at inspiration. ${ }^{6,7}$ Because flattening or anterior bowing of the posterior membranous wall of the trachea (ie, horseshoe-shaped trachea) is associated with submaximal inspiration, patients with this tracheal configuration were excluded. ${ }^{8,9}$

These CT scans were reviewed consecutively until we acquired 400 patients who met the entry and exclusion criteria for recruitment into the study. In total, $2375 \mathrm{CT}$ scans were reviewed to reach this quota. This was the training group and was used to create the fitted model. Patient selection for this group is summarized in Figure 2, A.

Using the same entry and exclusion criteria, we reviewed an additional 834 consecutive chest CT scans to obtain a separate group of 100 patients with normal chest CT scans, which constituted the testing group. This group was used to test the fitted model. Patient selection for this group is summarized in Figure 2, $B$. Within the testing group, there was a subset of 20 patients who had both contemporaneous CT and PFT who were used to compare predicted TLV (pTLV) with TLC for external validation of the model. This subset of 20 patients comprised the external model validation group.

\section{Lung Volume Measurement From CT Imaging}

Helical CT was performed using a 16-, 40-, or 64-multidetector CT scanner (Phillips Brilliance Series; Phillips Medical Systems, Best, the Netherlands), with patients in a supine position. The following parameters were used for the CT imaging: collimation, 0.625 to $0.75 \mathrm{~mm}$; tube voltage, 120 to $140 \mathrm{kV}$; and section thickness, 1 to $5 \mathrm{~mm}$. The scans were calibrated to include both lungs completely. The patients were instructed to hold their breath at deep inspiration. Each image series was assessed for proper quality and protocol adherence.

Postprocessing of images was performed using software on an independent workstation (Extended Brilliance Workspace; Phillips Medical Systems). This software allows for automatic segmentation of lungs based on a threshold density of $-750 \mathrm{HU}$ and region of interest, revealing $3 \mathrm{D}$ volume-rendered images. The trachea, up to the level of the thoracic inlet, was included in the volume measurements. Manual segmentation was additionally performed if misclassification of the digestive tract occurred. Split lung volumetric assessment was achieved 


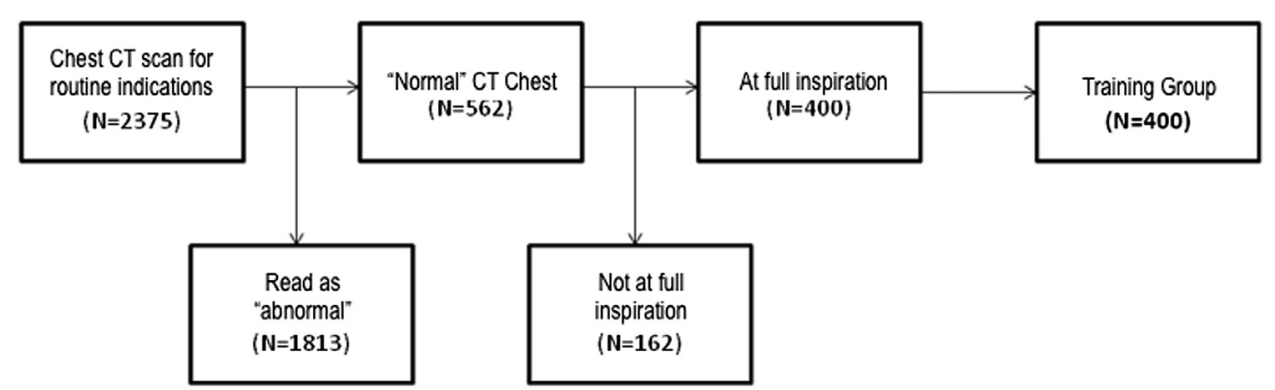

A

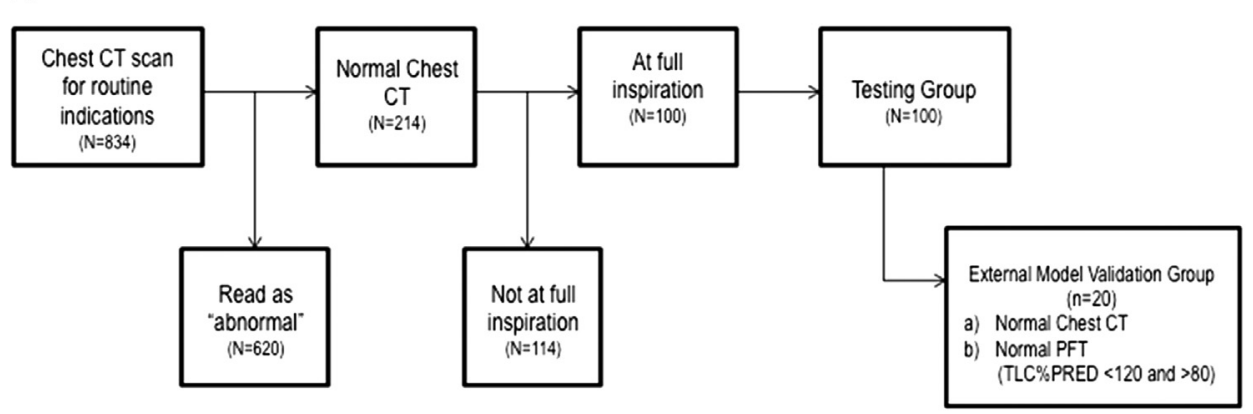

B

FIGURE 2. A, Summary of patients assessed, excluded, and included in the training group. B, Summary of patients assessed, excluded, and included in the testing group. $C T$, Computed tomography; $P F T$, pulmonary function test; $T L C \% P R E D$, percent predicted total lung capacity.

using manual segmentation, separating the 2 lungs down the midline of the trachea. The lung volumes were calculated automatically by the software as the sum of volumes of voxels included in the segmentation.

\section{Lung Volume Measurement From Body Plethysmography}

Retrospective chart review of the testing group was conducted. Of the 100 patients in this group, 20 patients were found to have undergone a synchronous normal body plethysmography study within 6 months of their CT scan. TLC was measured following guidelines established by the American Thoracic Society. ${ }^{10}$ TLC measurements were defined as normal if they were between $80 \%$ and $120 \%$ of the predicted TLC (pTLC) value for those individuals.

\section{Statistical Analysis}

Lung volumes-TLV, RLV, and LLV—were the response variables. Age, gender, race, height, body mass index, and body surface area were the predictor variables. The pTLV, predicted RLV (pRLV), and predicted LLV (pLLV), were obtained using the lasso regression ${ }^{11,12}$ with a 10 -fold cross-validation. The lasso regression simultaneously performs parameter estimation and variable selection and can prevent overfitting. We allocated 400 patients for training and 10-fold cross-validation, and we allocated 100 patients for testing. A predictor variable was considered to have a statistically significant contribution to lung volume if it was selected in the lasso regression. Comparisons between predicted and measured lung volumes were further achieved by computing Pearson's product-moment correlation. In the subset of patients with both a normal chest CT and a normal PFT, 3D-CT volumetry and PFT were correlated by comparing TLV to TLC, and pTLV to TLC.

\section{RESULTS}

\section{Predictive Lung Volume Equations}

The training group was used to construct the predictive equations. This population included 219 women and 181 men, with a mean age of 40 years (range, 18-55 years). The demographic and descriptive variables for the 400 patients in the training group are listed in Table 1. The overall mean 3D-CT volumetry measurements for TLV, RLV, and LLV were $4.23 \mathrm{~L}, 2.26 \mathrm{~L}$, and $1.97 \mathrm{~L}$, respectively.

Four variables were selected by the lasso regression as predictors of TLV, RLV, and LLV: age, gender, race, and height. Parameter estimate was achieved using the model, and predictive equations were created for TLV, RLV, and LLV (Figure 3). Demographic and descriptive variables and average 3D-CT lung volumes for the testing group of 100 patients are listed in Table 2.

TABLE 1. Demographic data and lung volumes for the training group $(\mathrm{n}=\mathbf{4 0 0})$

\begin{tabular}{lc}
\hline Demographic characteristic & Result \\
\hline Age $(\mathrm{y})$ & $39.8 \pm 10.3(18-55)$ \\
Men & $181(45.25)$ \\
Women & $219(54.75)$ \\
African American & $257(64.25)$ \\
Not African American & $143(35.75)$ \\
Height $(\mathrm{cm})$ & $169.8 \pm 11.7(123-201)$ \\
Weight $(\mathrm{kg})$ & $87.8 \pm 26.7(36-189)$ \\
Body mass index & $30.6 \pm 9.7(14-76)$ \\
Body surface area & $2.0 \pm 0.3(1.3-3.1)$ \\
Lung volumes $(\mathrm{L})$ & \\
$\quad$ Total lung volume & $4.23 \pm 1.14(1.79-7.52)$ \\
Right lung volume & $2.26 \pm 0.59(1.03-4.15)$ \\
$\quad$ Left lung volume & $1.97 \pm 0.56(0.76-3.53)$ \\
\hline Data are reported as mean \pm standard deviation (range) or $\mathrm{n}(\%)$.
\end{tabular}




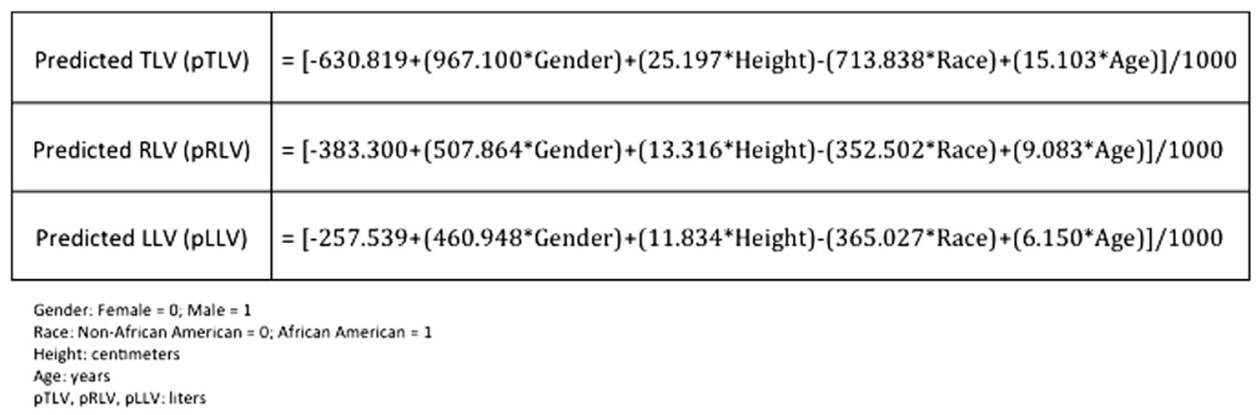

FIGURE 3. Predictive equations for predicted total lung volume ( $p T L V)$, predicted right lung volume ( $p R L V$ ), and predicted left lung volume ( $p L L V$ ). $T L V$, Total lung volume; $R L V$, right lung volume; $L L V$, left lung volume.

\section{Testing Predictive Equations: Predicted Lung Volume Versus Measured Lung Volume}

The predictive equations created from the training group were used to calculate pTLV, pRLV, and pLLV for the patients in the testing group. These volumes were plotted against the measured 3D-CT volumetry values for TLV, RLV, and LLV for these patients, respectively (Figure 4). There were strong linear correlations for pTLV versus TLV $(r=0.72 ; P<.0001 ; 95 \%$ confidence interval [CI], $0.60-0.80)$, pRLV versus RLV $(r=0.72 ; P<.0001 ; 95 \%$ CI, 0.61-0.80), and pLLV versus LLV $(r=0.69$; $P<.0001 ; 95 \%$ CI, 0.57-0.78). An additional model using only gender and height was constructed, but resulted in inferior predictive ability (Figure E1).

\section{Comparing 3D-CT Volumetry to PFT}

Data from the subset testing group who had a normal chest CT scan and a normal PFT were used to compare the predictive equation to measurements by PFT, by comparing TLV with TLC, and pTLV with TLC. Strong linear correlations were seen for TLV versus TLC $(r=0.79 ; P<.0001 ; 95 \% \mathrm{CI}, 0.54-0.91]$ ) (Figure 5, $A$ ),

TABLE 2. Demographic data and lung volumes for the testing group $(\mathbf{n}=\mathbf{1 0 0})$

\begin{tabular}{lc}
\hline Demographic characteristic & Result \\
\hline Age $(\mathrm{y})$ & $40.4 \pm 9.5(19-55)$ \\
Men & $43(43)$ \\
Women & $57(57)$ \\
African American & $55(55)$ \\
Not African American & $45(45)$ \\
Height $(\mathrm{cm})$ & $169.2 \pm 10.2(147-189)$ \\
Weight $(\mathrm{kg})$ & $85.8 \pm 23.1(47-157)$ \\
Body mass index & $30.2 \pm 8.6(14-70)$ \\
Body surface area & $2.0 \pm 0.3(1.4-2.8)$ \\
Lung volumes (L) & \\
$\quad$ Total lung volume & $3.38 \pm 1.01(1.88-7.37)$ \\
Right lung volume & $1.83 \pm 0.53(1.03-3.81)$ \\
Left lung & $1.55 \pm 0.50(0.82-3.58)$ \\
\hline Data are reported as mean \pm standard deviation (range) or $\mathrm{n}(\%)$.
\end{tabular}

and pTLV versus TLC $(r=0.82 ; P<.0001 ; 95 \% \mathrm{CI}$, 0.59-0.93) (Figure 5, B).

\section{DISCUSSION}

In an attempt to develop a new size-matching strategy in lung transplantation, we created predictive equations for donor lung volumes using readily available demographic characteristics - age, gender, race, and height. With the use of these predictive equations, donors' predicted lung volumes could in the future be compared with recipients' measured lung volumes by 3D-CT volumetry for size matching in lung transplantation.

The method of size matching for lung transplantation that is most widely used in the United States is height comparison between the recipient and donor. Height has been shown to be an important predictor of lung size and height mismatch is associated with donor-recipient size mismatch. ${ }^{13,14}$ Even further, height as a predictor of lung size has been time-tested; it has been successfully used as a predictor of lung transplantation success over the past 2 decades in the United States. However, data from our institution suggest that height is not the optimal predictor of lung volume in end-stage lung disease, either grossly over- or underestimating it. Size mismatch has been shown in recent years to play a significant role in allograft function and bronchiolitis obliterans syndrome. Eberlein and colleagues $^{3}$ showed a $22 \%$ absolute increase in bronchiolitis obliterans syndrome in undersized lungs compared with oversized lungs after bilateral lung transplantation. ${ }^{3}$ These authors also showed an $8 \%$ absolute decrease in forced expiratory volume in 1 second/forced vital capacity ratio in the same cohorts.

Although other size-matching strategies have sporadically been described, including chest roentgenogram dimensions, inframammary circumference, and vital capacity, ${ }^{15-17}$ the only other widely used methods are donor pTLC versus recipient pTLC and donor pTLC versus recipient actual TLC. For pTLC, the PFT predictive equations were created based on PFT measurements in a normal population. ${ }^{18-22}$ Interestingly, 

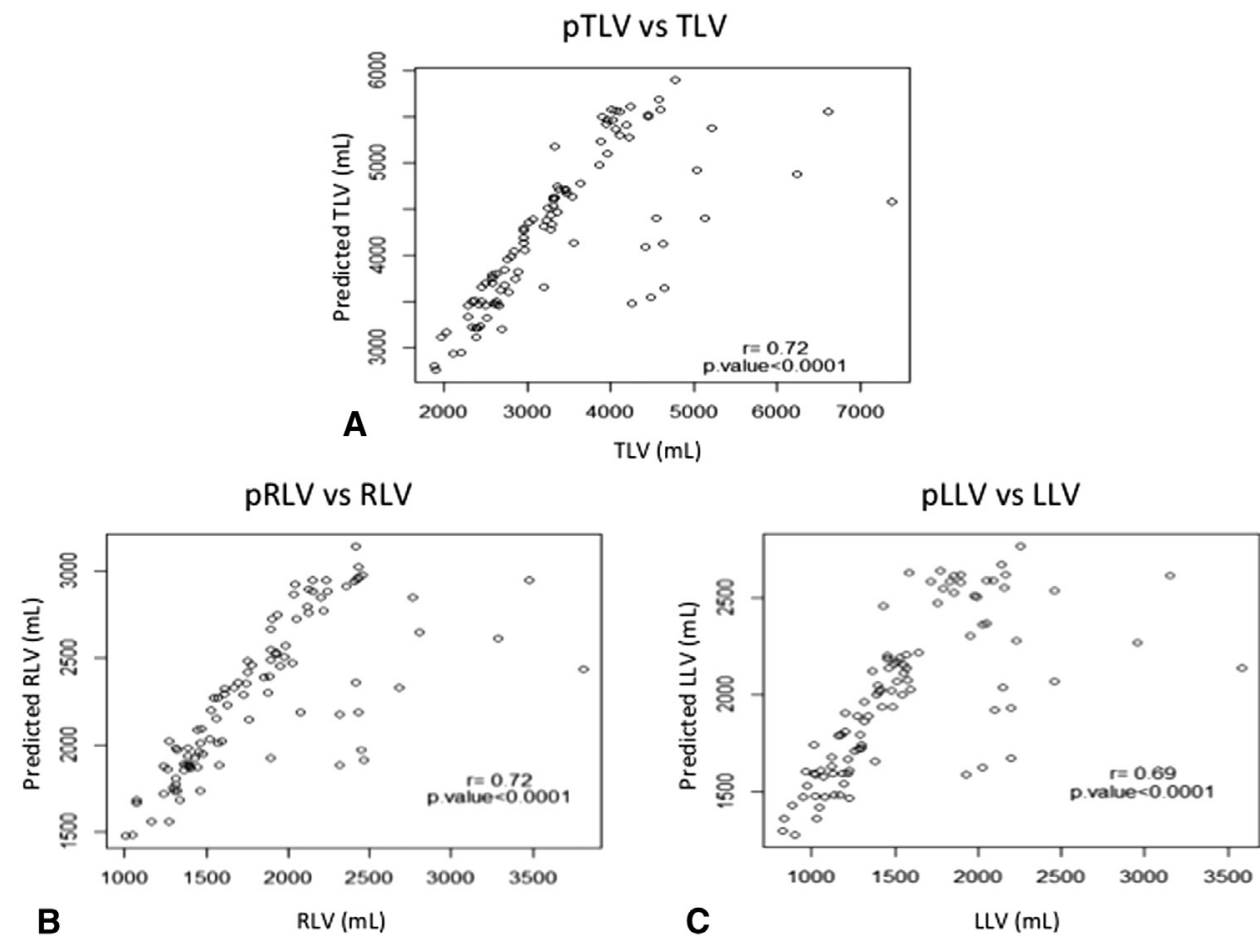

FIGURE 4. Correlations of predicted lung volumes versus actual lung volumes measured by 3-dimensional computed tomography volumetry in the testing group. A, Predicted total lung volume ( $p T L V)$ versus total lung volume $(T L V)$. B, predicted right lung volume ( $p R L V$ ) versus right lung volume $(R L V)$. $\mathrm{C}$, Predicted left lung volume ( $p L L V)$ versus left lung volume $(L L V)$.

Crapo and colleagues ${ }^{19}$ equations do not incorporate age or race, which were shown in our study to be independent predictors of TLV, RLV, and LLV. This may explain why the regression equations we developed account for a greater degree of variance than those published for men $(r=0.54)$ and women $(r=0.60)$ by Crapo and colleagues ${ }^{21}$ for TLC. Similarly, we created a 3D-CT volumetry model using only height and gender as predictors to analyze the predictive ability of the 2 variables deemed important from Crapo and colleagues. ${ }^{21}$ However, this was found to have an inferior predictive ability compared with the included model.

Whereas the donor pTLC to recipient pTLC strategy has its merits, studies have shown that this is associated with a high degree of variance when compared with actual measured volumes. ${ }^{13,23}$ Specifically, in idiopathic pulmonary fibrosis, Mason and colleagues ${ }^{13}$ showed that although the mean pTLC ratio was 0.95 , the mean actual TLC ratio was 1.93. Although this discrepancy may be limited by comparing donor pTLC to recipient actual TLC, this method still may be limited in comparison to a 3D-CT volumetry-derived strategy. Brown and colleagues ${ }^{5}$ concluded that CT imaging was significantly more reproducible than PFT, with a higher correlation in serial lung volume measurements compared with PFT. This study suggests that 3D-CT volumetry may provide lung volumes that are superior to TLC in reliability and reproducibility.
An additional benefit to measuring lung volumes using 3D-CT volumetry over PFT is that TLC measures static inspiratory volume, which indicates lung function, whereas TLV is an anatomic measurement. As a result, TLC only accounts for alveolar space, and therefore it may underestimate volume in patients with restrictive disease or atelectasis. ${ }^{24}$ 3D-CT would be able to account for this volume. Furthermore, 3D-CT volumetry allows evaluation of individual lung volumes, enabling assessment of disease in the left and right lungs individually. ${ }^{25}$ Because single-lung transplantation continues to account for a significant proportion of total lung transplants, these equations may offer a unique advantage in size matching for bilateral as well as single-lung transplantation. ${ }^{26}$

\section{Limitations}

It is difficult to definitively know that patients are at full inspiration during CT imaging. When performing PFTs, patients are coached by technicians to fully inspire upon testing. ${ }^{6,27}$ Although CT technicians insist that patients take a full inspiration, patients are not consistently coached on breathing techniques before CT. Chest CT scans with flattening or anterior bowing of the posterior membranous tracheal wall were excluded from this study because these configurations are consistent with submaximal inspiration.,

Additionally, our study does not provide insight to the degree of variance between pTLV and recipient TLV that 


\section{TLV vs TLC}
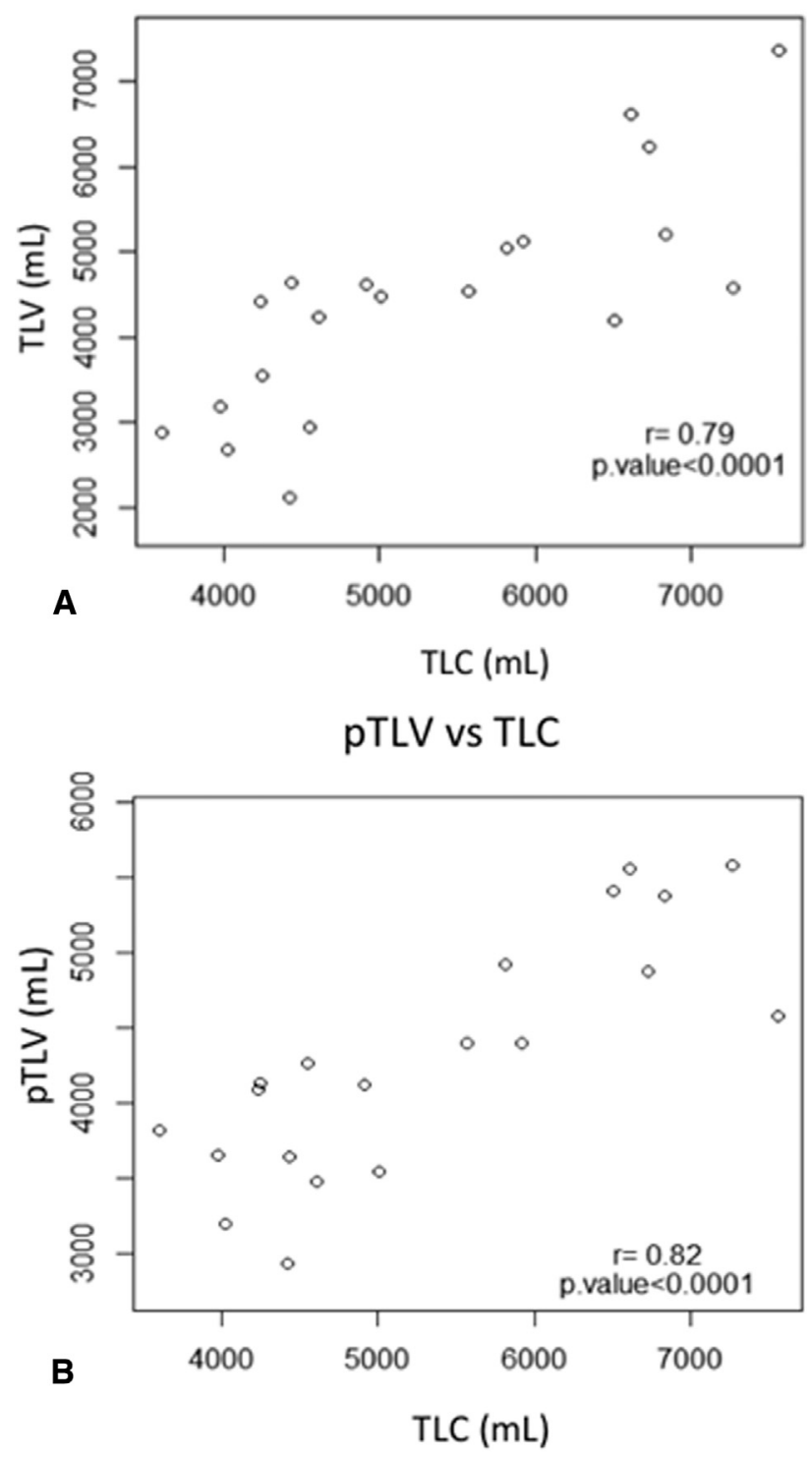

FIGURE 5. A, Correlations of measured total lung capacity ( $T L C$ ) versus measured total lung volume (TLV) in subset of 20 patients from the testing group with normal chest computed tomography $(C T)$ and normal pulmonary function test $(P F T)$. B, Correlations of measured TLC versus predicted total lung volume $(p T L V)$ in subset of 20 patients from the testing group with normal chest CT and normal PFT.

should be deemed acceptable, nor does it directly compare the size-matching accuracy to TLC or other size-matching options. With these predictive equations, these questions and hypotheses now can be evaluated in future, prospective trials.

\section{CONCLUSIONS}

We successfully constructed predictive equations for TLV, RLV, and LLV, using lung volumes of 400 individuals obtained by 3D-CT volumetry, that only require gender, age, race, and height as variables. The predictive equations created correlate strongly with measured volumes. They may open the door to many new possibilities in the application of 3D-CT volumetry in various fields, particularly in lung transplantation. Using these equations, we hope to perform a prospective study assessing the clinical utility of a 3D-CT volumetry-derived size-matching strategy to improve outcomes in lung transplantation.

\section{Conflict of Interest Statement}

Authors have nothing to disclose with regard to commercial support.

The authors thank Charles White, MD, Nevins Todd, MD, Brandi Knight, MD, Brigitte Pocta, and Allison B. McCoy, PhD, for providing intellectual, data collection, and editing contributions.

\section{References}

1. Ouwens JP, van der Mark TW, van der Bij W, Geertsma A, de Boer WJ, Koeter GH. Size matching in lung transplantation using predicted total lung capacity. Eur Respir J. 2002;20:1419-22.

2. Krishnam MS, Suh RD, Tomasian A, Goldin JG, Lai C, Brown K, et al. Postoperative complications of lung transplantation: radiologic findings along a time continuum. Radiographics. 2007;27:957-74.

3. Eberlein M, Reed RM, Bolukbas S, Diamond JM, Wille KM, Orens JB, et al. Lung size mismatch in bilateral lung transplantation is associated with allograft function and bronchiolitis obliterans syndrome. Chest. 2012;141:451-60.

4. Iwano S, Okada T, Satake H, Naganawa S. 3D-CT volumetry of the lung using multidetector row CT: comparison with pulmonary function tests. Acad Radiol. 2009; 16:250-6

5. Brown MS, Kim HJ, Abtin F, Da Costa I, Pais R, Ahmad A, et al. Reproducibility of lung and lobar volume measurements using computed tomography. Acad Radiol. 2010;17:316-22.

6. Kauczor HU, Heussel CP, Fischer B, Klamm R, Mildenberger P, Thelen M. Assessment of lung volumes using helical CT at inspiration and expiration: comparison with pulmonary function test. AJR Am J Roentgenol. 1998;171: 1091-5.

7. Yamashiro T, Matsuoka S, Bartholmai BJ, San José Estépar R, Ross JC, Diaz A, et al. Collapsibility of lung volume by paired inspiratory and expiratory CT scans: correlations with lung function and mean lung density. Acad Radiol. 2010; 17:489-95.

8. Lee EY, Boiselle PM. Tracheobronchomalacia in infants and children: multidetector CT evaluation. Radiology. 2009;252:7-22.

9. Lee EY, Tracy DA, Bastos MD, Casey AM, Zurakowski D, Boiselle PM. Expiratory volumetric MDCT evaluation of air trapping in pediatric patients with and without tracheomalacia. AJR Am J Roentgenol. 2010;194:1210-5.

10. Wanger J, Clausen JL, Coates A, Pederson OF, Brusasco V, Burgos F, et al. Standardisation of the measurement of lung volumes. Eur Respir J. 2005;26:511-22.

11. Tibshirani R. Regression shrinkage and selection via the lasso. J R Stat Soc Series B. 1996;58:267-88.

12. VIdaurre D, Bielza C, Larrañaga P. Lazy lasso for local regression. Comput Stat. 2012;27:531-50.

13. Mason DP, Batizy LH, Wu J, Nowicki ER, Murthy SC, McNeill AM, et al. Matching donor to recipient in lung transplantation: how much does size matter? J Thorac Cardiovasc Surg. 2009;137:1234-40.

14. Eberlein M, Reed RM, Permutt S, Chahla MF, Bolukbas S, Nathan SD, et al. Parameters of donor-recipient size mismatch and survival after bilateral lung transplantation. J Heart Lung Transplant. 2012;31:1207-13.

15. Miyoshi S, Demertzis S, Eckstein F, Hohfeld J, Schaefers HJ. Chest size matching in single and double lung transplantation. Jpn J Thorac Cardiovasc Surg. 1999;47:163-70.

16. Miyoshi S, Schaefers HJ, Trulock EP, Yamazaki F, Schreinemakers H, Patterson GA, et al. Donor selection for single and double lung transplantation. Chest size matching and other factors influencing posttransplantation vital capacity. Chest. 1990;98:308-13. 
17. Park SJ, Houck J, Pifarre R, Sullivan H, Garrity E, Kim SY, et al. Optimal size matching in single lung transplantation. J Heart Lung Transplant. 1995;14: 671-5.

18. Baur X, Isrignhausen-Bley S, Degens P. Comparison of lung-function reference values. Int Arch Occup Environ Health. 1999;72:69-83.

19. Crapo RO, Morris AH, Gardner RM. Reference spirometric values using techniques and equipment that meet ATS recommendations. Am Rev Respir Dis. 1981;123:659-64

20. Morris JF, Koski A, Johnson LC. Spirometric standards for healthy nonsmoking adults. Am Rev Respir Dis. 1971;103:57-67.

21. Crapo RO, Morris AH, Clayton PD, Nixon CR. Lung volumes in healthy nonsmoking adults. Bull Europ Physiopath Respir. 1982;18:419-25.

22. Goldman H, Becklake M. Respiratory function tests: normal values at median altitudes and the prediction of normal results. Am Rev Tuberculosis Pulmon Dis. 1959;79:457-67.

23. Loizzi D, Aigner C, Jaksch P, Scheed A, Mora B, Sollitto F, et al. A scale for decision making between whole lung transplantation or lobar transplantation. Eur J Cardiothorac Surg. 2010;37:1122-5.
24. Bernard JB, Davies O, Curry P. Size matching in lung transplantation: an evidence-based review. J Heart Lung Transplant. 2013;32:849-60.

25. Camargo JJ, Irion KL, Marchiori E, Hochhegger B, Porto NS, Moraes BG, et al Computed tomography measurement of lung volume in preoperative assessmen for living donor lung transplantation: volume calculation using 3D surface rendering in the determination of size compatibility. Pediatr Transplant. 2009;13:429-39.

26. Christie JD, Edwards LB, Kucheryavaya AY, Benden C, Dobbels F, Kirk R, et al. The Registry of the International Society for Heart and Lung Transplantation: twenty-eighth adult lung and heart-lung transplant report-2011. J Heart Lung Transplant. 2011;30:1104.

27. Schlesinger AE, White DK, Mallory GB, Hildeboldt CF, Huddleston CB Estimation of total lung capacity from chest radiography and chest CT in children: comparison with body plethysmography. AJR Am J Roentgenol. 1995;165:151-4.

Key Words: computed tomography, lung, organ donor management, regression analysis, lung transplantation

Readers who found these articles interesting may also like to read the following papers found in recent and future issues of our sister publications, Seminars in Thoracic and Cardiovascular Surgery and Operative Techniques in Thoracic and Cardiovascular Surgery!

\section{Transplantation}

Original Submission: Trends in U.S. Extracorporeal Membrane Oxygenation Use and Outcomes: 2002-2012. Fenton H McCarthy. Semin Thorac Cardiovasc Surg 2015; Summer; 27(2):81-88.

Editorial Commentary: Is it Worth it to Increase the Use of Extracorporeal Membrane Oxygenation? Marco Morsolini. Semin Thorac Cardiovasc Surg 2015; Summer; 27(2):89-90.

Original Submission: Increased Procurement of Thoracic Donor Organs After Thyroid Hormone Therapy. Dimitri Novitzky. Semin Thorac Cardiovasc Surg 2015; Summer; 27(2):123-133.

Editorial Commentary: Optimizing Donor Quality Via Hormonal Therapy: An Important Strategy to Increase Successful Placement of Thoracic Organs in End-Stage Patients. Syed M. Peer. Semin Thorac Cardiovasc Surg 2015; Summer; 27(2):133-134.

State of the Art: The State of the Art in Corporeal Membrane Oxygenation. Steve K. Singh. Semin Thorac Cardiovasc Surg 2015; Spring; 27(1):17-23.

Median Sternotomy for Lung Transplantation. John Dark. Oper Tech Thorac Cardiovasc Surg 2015; Spring; 20(1):87-103.

Less Invasive Techniques for Left Ventricular Assist Device Implantation. Scott C. Silvestry. Oper Tech Thorac Cardiovasc Surg 2015; Summer; 20(2):189-203.

Ex Vivo Lung Perfusion. Marcelo Cypel. Oper Tech Thorac Cardiovasc Surg 2014; Winter, 19(4): 433-442.

Subcostal Approach to Replacement of a HeartMate II Device: Indications and Technique. Nader Moazami. Oper Tech Thorac Cardiovasc Surg 2014; Winter, 19(4):443-453. 


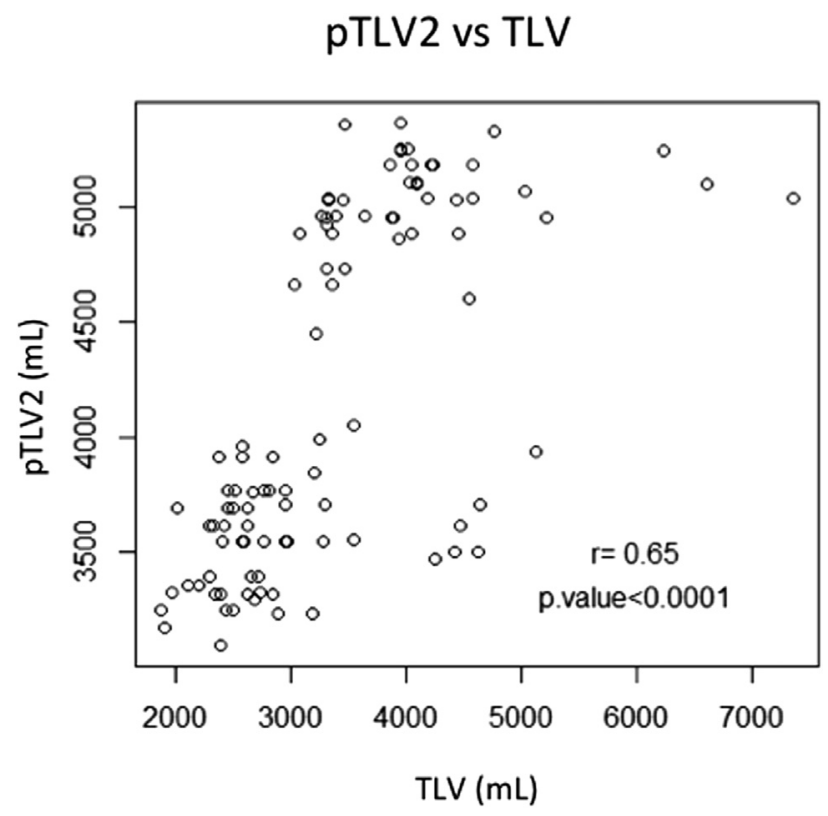

FIGURE E1. Correlations of predicted lung volume ( $p T L V)$ using gender and height only versus actual total lung volume (TLV) measured by 3-dimensional computed tomography volumetry in the testing group. 